\title{
Increasing the Potential for Gaze, Surveillance and Normalisation: the transformation of an Australian policy for people who are homeless*
}

\author{
Rodney Fopp'
}

\begin{abstract}
Michel Foucault analysed the origins and social function served by institutions such as the prison and the clinic, explored the links between knowledge and power, and the body as a location or site of such social power. In this article, Foucault's analysis is applied to an Australian program for people who are homeless. After outlining a theoretical framework which emphases Foucault's theme of increasing surveillance being used for the purposes of greater regulation and control, this article analyses the changes that have occurred in the program. It is argued that initially the program was intended to assist non-government agencies to provide a range of services, including short-term crisis accommodation services, after which clients would move to independent housing. However, due to the lack of affordable and appropriate houses for clients to enter after their stay in agencies, clients have been forced to stay in funded agencies for longer than is otherwise necessary. Among other things, this program has adapted by providing more short-to-medium term accommodation and case management for clients which, in turn, has led to an extension of the time clients remain in agencies and greater intensity of service provision. It is argued that this has resulted in increased potential for surveillance, control and regulation.
\end{abstract}

\section{Introduction}

One legacy of Michel Foucault's work has been the connection he forged between increasing surveillance, on the one hand, and escalating control and regulation, on the other. Consequently, there has been a renewed interest in the locations and characteristics of power, and the human body as a site on which power is exerted. This is not to suggest that power is deterministic or uni-directional, vertically orientated or only 'top-heavy' or 'top-down'. According to Foucault, power is contested, often paradoxical and contradictory, and there may be (seeming) tensions in the way it is exercised.

\footnotetext{
* The author would like to thank Stephen Parker, research assistant in the School of International Relations, for his editorial assistance and comments on an earlier draft of this paper. The author is responsible for all the views herein.

${ }^{1}$ Senior Lecturer: Sociology, University of South Australia, Magill Campus, St Bernards Rd., South

Australia, Australia 5072. rodney.fopp@unisa.edu.au
} 
Whether power so understood is a disguise to divert attention away from its more coercive and peremptory forms is a moot point. Conceivably, groups and individuals who have it, also have the power to conceal and distort, to camouflage and deflect attention away from any clandestine objectives. Nonetheless, Foucault's analysis of axes, nodes or nodules of power also provides the opportunity to focus on the self as a site of power, particularly on the lower rungs of the ladders of authority.

The link between power and surveillance is identifiable in Foucault's analysis of the panopticon. This involved the arrangements of buildings so guards of a prison could monitor all the activities of the inmates without their knowledge. In the twentieth century electronic surveillance increasingly became a substitute for such personal observations. Nonetheless, even today in, for example, classrooms, clinics and hospitals people (Cheek and Rudge 1993), in research programs and at the counters of government social security agencies, the sort of scrutiny Foucault identified occurs with increasing sophistication.

Institutions have been typically characterised by inspection and, in the late nineteenth and early twentieth centuries, institutional solutions to social problems were prevalent. It is generally agreed that, from the 1870 s on, mass education in the West was as much a solution to the 'problem' of children roaming the streets as it was preparing a (domestic and industrial) workforce for the burgeoning and increasingly complex industrialisation occurring at the time.

By contrast, it might be anticipated that de-institutionalisation, such as the closure of psychiatric hospitals, may also reduce the extent of surveillance. While often couched in terms of freeing people to live in the community, or justified as more appropriate, private accommodation or non-institutional, non-residential settings do not necessarily entail less supervision or monitoring. In fact, if more government and other agencies are involved in supervision, it may entail more regulation.

What about people who are literally homeless? What is the extent of the surveillance when people who are homeless enter residential, small, emergency crisis refuges or shelters? What data is collected about them? How are they calibrated and classified? While they are in shelters, what sort of interventions by human service and other professionals occur? Does the intervention increase when they are moved to medium (say up to three months) or longer term supported accommodation (say up to 12 months)?

Furthermore, does the potential for intervention increase because there is little affordable and appropriate accommodation to which people could move after the accommodation provided by agencies? If there is no where else to go, and they are forced to stay in agency-provided accommodation longer than is necessary, is the potential for gaze and control increased? Does remaining longer than is necessary create a bottleneck, preventing other people who are homeless from entering crisis accommodation? What is the social function of the ever-present and visible backlog of people who are living on the streets, or going from one agency to another, seeking accommodation? 
This article explores the increasing potential for intervention in a program for the estimated '50,000-100,000 people at any one time' who are homeless in Australia (SEAC and AHURI 1999: 1). A person is homeless, according to the program under review, if they have 'inadequate access to safe and secure housing'. This includes housing which may be deleterious to health or safety, has inadequate personal amenities or is unaffordable (Commonwealth of Australia 1994).

In a nutshell, the argument in the following is that changes in the program to be examined have increased the potential for scrutiny. This potential has been accentuated by the trend for clients to stay in the program longer than would otherwise be necessary which, in itself, has lead to greater levels of intervention. The reason for staying in agency accommodation longer than necessary is because there is nowhere else to go which, in turn, is the result of the lack of affordable and appropriate accommodation after the program.

The lack of affordable and appropriate accommodation and housing is, in part, the result of government policy which has cut the availability of public housing while, simultaneously, providing enormous incentives to the private rental and home-ownership sectors. Such policy developments have their origins in broader economic policies designed to free markets by limiting government interference in the economy. While the broader economic policy has influenced housing policy, this article will concentrate on aspects relevant to scrutiny and intervention pertinent to the program under review.

The article begins by introducing the relevant program for people who are homeless. The next section outlines relevant aspects of Foucault's work in order to provide a theoretical framework for the subsequent policy analysis. After the policy analysis, which is the substantial part of the paper, several implications emanating from the analysis are examined.

\section{The program under review - a brief history and summary}

The program examined in this paper is known the Supported Accommodation Assistance Program (and usually by its acronym SAAP). Introduced in 1985 by the Australian Government, SAAP is a jointly-funded venture between the Federal and State and Territory governments. It grants funding to non-government agencies to enable them to provide supported accommodation and other forms of support to homeless people. The prime objective of the original SAAP was to assist people who were homeless to move to independent accommodation, usually as renters.

Since the fledgling SAAP, or SAAP I as it became known, the Program has been evaluated nationally. These official National Evaluations have provided the basis for policy development, and have formed the basis of the subsequent new agreements between the Federal and State Governments. Thus, SAAP II, III and IV (SEAC and AHURI 1991: 2) were enshrined in new legislation in 1989, 1994 and 2000. It is the 
developments within and between SAAP Mark I, II, III and IV that provide the unfolding evidence on which the following analysis and argument are based.

Prior to SAAP there was a diverse range of largely un-coordinated Australian State and Commonwealth (Federal) government programs for people who were homeless. Different eligibility and funding conditions applied. The new Program, which began in 1985, was intended to streamline the different programs, and co-ordinate funding arrangements between the States and the Commonwealth of Australia.

The fledgling SAAP could be regarded as a moderately progressive policy, that is, as an attempt to assist a most disadvantaged group by providing emerge ncy accommodation and other support. The accommodation and support provided was intended to place clients in a position of being able to compete in the private and public rental sectors and live in their own independent accommodation, that is, no longer homeless.

Originally SAAP was intended to provide funds for non-government agencies (such as those run by Salvation Army, St Vincent de Paul and various community-based organizations). The agencies used the funds to provide accommodation and other support facilities (such as, for example, meals and shower facilities) in order that clients could move to accommodation of their own.

The intention was that clients who so required would stay in SAAP funded crisis or emergency accommodation for short periods of time (perhaps a month). In that time workers would be able to ensure that they had a social security income, and would be able to negotiate their own rental accommodation in the private or public (government funded) housing sectors. They would no longer be homeless.

The first SAAP, or SAAP I, emphasised this 'moving on' objective. It was as if the provision of funding to provide supported accommodation, and other support services, was a subsidiary goal to the main objective of independent living. SAAP was the means to the end - 'moving to independent living', attaining their own 'home'. While modified, this remains a SAAP objective although, as will be argued, subsequent developments have adversely influenced such outcomes.

Now that the Program under discussion has been briefly examined, the discussion turns to the theoretical material which will inform the policy analysis. In the following three aspects of Foucault's analysis will be outlined in order to highlight the tools of analysis used in the remainder of the paper.

\section{The theoretical framework for the analysis}

\section{Increasing observation}

One aspect of Foucault's work which can be applied to the Program for people who are homeless is the significance he attributed to Jeremy Bentham's 'Panopticon' (Foucault 1979: 200; Shawver 1998). The panopticon was an arrangement of light, space and 
architecture. The rooms in the buildings had two windows, one away from a centrally located tower and the other facing it. Such use of light, space and building enabled inmates or residents to be under the gaze of an official at all times (Foucault 1979: 170174).

According to Foucault, the increased observation and surveillance enabled by the panopticon is replicated in many ways in other settings, including classrooms, clinics, hospitals and prisons (Foucault 1979: 204). Exemplifying the relevance of Foucault's analysis are the following questions: Does SAAP operate to increase observation and surveillance? Without being a prison, does SAAP increase the potential for greater scrutiny?

Observation in order to increase control and regulation

Secondly, according to Foucault, surveillance is a means to another end. It is not only about the impact of increasing observation and supervision as colloquially understood (or to protect, as might be expected of a teacher, parent or care-giver). For Foucault, this observation involves more than mere looking or observing. Surveillance involves control, regulation and supervision. As he claimed (Foucault 1979: 204):

The Panopticon functions as a kind of laboratory of power. Thanks to its mechanisms of observation, it gains in efficiency and in the ability to penetrate into men's [sic] behaviour; knowledge follows the advances of power, discovering new objects of knowledge over all the surfaces which knowledge is exercised.

The aim of surveillance is regulation and control which he articulated in several different ways, one of which was 'bio-power' (Dreyfus and Rabinow 1982: 133-142; Shawver 1998). This refers to the control exerted over people and, specifically over their bodies and minds, in order to induce compliance, transformation or render them docile (1991 [1978]: 265). He also called such control 'disciplinary technologies' (Foucault 1979: 215), 'technologies of power' or 'technologies of domination' (Foucault 1988: 18-19; Shawver 1998).

The emphasis here is on Foucault's general thrust rather than the mechanics of how the domination occurs. So, the surveillance is purposive; the aim is to control and change people. The question for our purposes becomes: Does SAAP serve as a site for technologies of power and domination? Does it exert bio-power? If so, what attests to it?

The methods of domination

If the first point above was about observation, and the second was about the purpose or objective of the scrutiny (namely, exerting power and normalisation), the third is about the specific means or the methods by which the control and regulation occurs. According to Foucault, contemporary technologies of domination do not necessarily involve torture and death-squads but, for example, the seemingly more benign influence exerted over persons by, for example, those trained in the medical and social sciences (Foucault 1982: 211-222). 
As applied to people who are homeless this could involve dividing and segregating the homeless from the remaining population so that the socially constructed 'problem' is continuously before the public gaze (Foucault 1982: 208). It could also include the necessary precursors to intervention, including being classified or labelled according to various statistical measures which are socially ordained (perhaps using 'normal distribution curves').

According to Foucault, the aim of the ensuing intervention is 'normalisation' meaning that, for example, the person's behaviour, health and housing status are transformed to come within social acceptable standards. This normalisation (Foucault 1979: 177ff) uses socially approved or credited disciplinary technologies such as counselling or therapy, or other means of behaviour modification given by experts, whose diagnosis and treatment is outside the arena of political debate (Foucault 1991: 266-267). In this way, any contentious issues or debate is neutralised; it is the hands of the experts.

\section{Research Questions}

For the purposes of this analysis the salient issue is whether SAAP has the potential to increase the gaze, the surveillance, thereby enhancing the potential for power or technologies of domination, which can be exerted over clients. As a program, does SAAP measure, diagnose, test and intervene with the result that the residents are targets of bio-power or technologies of power? Indeed, I wish to be more specific because this article is about identifying the increasing potential for more surveillance, intervention and control. The salient question then is: does SAAP have the potential to serve as a location for the actual practices of bio-power? Does it have the potential to be a laboratory of power?

Do clients stay in SAAP accommodation services longer than is necessary, thus increasing the potential for the operation of what might be called 'technologies of domination' (by virtue of staying longer)? Are there specific policies which have been introduced in SAAP over time which by themselves increase the control over clients (irrespective of the longer time spent in SAAP services because of the lack of exit points)?

The paper now turns to the policy analysis in which the research questions are addressed. The discussion begins with a brief contextual explanation for the lack of accommodation options after SAAP, before embarking on an analysis which outlines the lack of postSAAP options and their deleterious implications for clients.

\section{The lack of affordable housing in Australia.}

The success of SAAP I (and SAAP II, III, IV for that matter) depended on the existence of affordable and appropriate accommodation outside SAAP. This was the 
accommodation in which ex-clients could live subsequent to the support and refuge which was provided by a SAAP agency. Appropriate (that is, not too large or small for the single person or the household type) and affordable accommodation or housing (that is, within the person's or household's means), was required.

Another option, 'the great Australian dream' of purchasing and then owning a home, is obviously unavailable to SAAP clients who are homeless. The other post-SAAP alternatives are renting in the private sector or in 'public housing'. As there is a dearth of cheaper rental properties at the lower end of the market, private renting is often too expensive for people who are ready to exit SAAP. There is a 'rent allowance' for Government social security beneficiaries but this is usually insufficient to make private rental viable and sustainable.

The other alternative, public housing, is provided under the Commonwealth/State Housing Agreement which makes available subsidised accommodation, the rent of which is calculated as a specific proportion of income (often under 25 per cent, irrespective of income). This is usually an ideal option for clients ready to leave SAAP accommodation.

However, under the influence of free-market policies, public housing has suffered funding cuts so allocation policies have increasingly been directed at those most 'in need'. Public housing, once available to most Australians, is increasingly becoming 'welfare housing' while funding cuts and huge demand (attested by long waiting lists), have resulted in this most viable housing option being unavailable to SAAP clients when they are ready for it. The net result of this cluster of policies (and others) is the lack of appropriate and affordable options for SAAP clients who are ready to move on. Exiting SAAP is difficult. Thus the problem is known as the lack of 'exit points'.

\section{The lack of exit points}

The three official National Evaluations of the Program have all emphasised the lack of exit points. For example, the first National Evaluation noted that 'improvements in SAAP are dependent on major changes in related health, welfare and housing systems' and the need for more public housing (Chesterman 1988: 36; 87).

By the time of the second Evaluation (1993) the issues were obvious although the evaluation was more specific, and referred to:

1. workers being 'constrained' by the lack of access to suitable housing for many of their users' (Lindsay 1993: 46; emphasis added);

2. contributors to the Evaluation recognising that the lack of exit points ... was a serious barrier to SAAP's fulfilment of its role as a program in transition' (Lindsay 1993: 60; emphasis added); 
It also stated that 'the most intractable problem facing $S A A P$ is the lack of suitable, affordable housing for SAAP users when they leave SAAP services' (Lindsay 1993: 107; emphasis added). Here, the lack of exit points is clear.

The problem of exit points continued throughout the 1990s. In the context of the discussion of client outcomes, the most recent National Evaluation (SEAC and AHURI 1999: 57) noted that '[m]ajor concerns were expressed about the inadequacy of existing arrangements with respect to "entry" and "exit" points from SAAP.' The problem of 'entry' refers to potential clients being turned away from agencies partly because of the backlog caused by the bottleneck in SAAP (caused, in part, by the lack of exit points).

Regarding the aim of moving to independent, the same evaluation also noted that the State/Territory Evaluation Reports indicated the difficulties SAAP services have in meeting this aim in 'the absence of adequate exit points or when clients have high and complex needs' (SEAC and AHURI 1999: 105; emphasis added). Thus, in the third national Evaluation the problem of exit points was raised again. It is a continuing theme.

\section{Remaining in SAAP accommodation longer than is necessary: greater potential for increased levels of intervention}

Thus far, the emphasis has been on the lack of exit points per se. One consequence of this lack has been that clients remain in SAAP agencies longer than necessary. In this way, they are under the gaze for longer periods of time than would be the case if there were post-SAAP accommodation options. As the first National Evaluation noted:

Improvements in the SAAP system are dependent on major changes in related health, welfare and housing systems. For example, women will stay in a refuge longer than is necessary or appropriate because they have no possibility of getting a public housing placement (Chesterman 1988: 36; emphasis added).

The theme was also evident in the second National Evaluation (Lindsay 1993: 46, 75, $107,120)$ which included the following statement.

The absence of suitable 'exit points' has significant detrimental consequences for SAAP, forcing users to remain in services longer than would otherwise be necessary, thus undermining the transitional focus of the Program (Lindsay 1993: 4; emphasis added).

Here we can detect a decisive point in the argument: the protracted length of time in SAAP has provided the opportunity for a more interventionist approach. As the first National Evaluation stated:

One of the clearest things we can deduce is that without a range of public housing options which cater for SAAP clients they will be forced to utilize the more costly and intensive SAAP services, even when they are not 
appropriate, purely because of the lack of public housing (Chesterman 1988: 87; emphasis added).

The second National Evaluation also noted that the lack of post-SAAP accommodation options 'forces some people to remain in SAAP services when their need for support has passed, and adversely affects access by others' (Lindsay 1993: 107; emphasis added). The same report also pointed out that there were several factors beyond the control of SAAP which adversely affected outcomes for users:

The most important of these is the availability of affordable housing. The absence of such housing forces into SAAP services people who are houseless rather than homeless and who do not need the intensive support which SAAP is designed to provide. It forces other SAAP users to remain in services long after their need for intensive support has passed. It reduces SAAP's ability to achieve optimum outcomes for each of these groups, in accordance with SAAP objectives (Lindsay 1993: 75; emphasis added).

Thus, some clients who do not need intensive support receive it because of the lack of exit points; users who remain in SAAP longer than is necessary receive support after their need has passed. The same point is dentified in the evaluation of SAAP III: 'increased demand is related to the inadequacies in exit point access, making for longer stays in SAAP accommodation' (SERC and AHURI 1999: 53; emphasis added).

The above analysis has established that SAAP clients remain in SAAP accommodation facilities longer than is necessary because of the lack of exit points. Official evidence has also been adduced to support the conclusion that SAAP has the potential to be the site of observation and surveillance, for more intrusive interventions. Our attention turns to what actually has happened to SAAP in order to identify the scrutiny and management of clients.

\section{Specific changes to SAAP which have increased the potential for surveillance and management}

From crisis (short-term) to transition

The influence of exit points can be seen in the changes to the Program, and particularly the change in focus from crisis services in SAAP I to 'transitional accommodation and related support services' in SAAP II (Lindsay 1995, p. 22). This involved a move from traditional 'welfare' approaches and 'refuges' to linkages with other mainstream programs and agencies (Lindsay 1993, p. 23-24).

One reason for the modification was that the shortfall in post-SAAP accommodation necessitated more short-to-medium accommodation in SAAP. In other words, while SAAP I was characterised by more crisis and emergency accommodation (under 4 weeks in refuges and shelters), SAAP II, III and IV have seen an increase in medium-long term 
accommodation (3-12 months). With his policy change - from crisis to transition clients also remain longer.

Arguably, this change to transition was a response, at least in part, to the lack of exit points. But have there been other program changes which increase the potential for observation and control? The following attempts to answer the question more specifically by examining some of the changes in the aims and objectives of SAAP between 1985-2000.

SAAP I was intended to grant funds to non-government agencies in order for them to provide:

a range of supported accommodation services and related support services, to assist men, women, young people and their dependents who are permanently homeless, or temporarily homeless as a result of crisis, and who need support to move toward independent living, where possible and appropriate (Chesterman 1988: 10).

This objective was questioned in the first National Evaluation on the grounds that it 'is wasteful of scarce resources to provide support to users of SAAP services whose primary need is low cost, low support accommodation (Chesterman 1988: 44). This was the beginning of the move away from a moderately progressive program to one that was more interventionist.

The first National Evaluation recommended that only people in both personal crisis and bereft of accommodation should be included in the SAAP target group (Chesterman 1988: 47). That people without accommodation might be critically in need of support to obtain accommodation, was not considered in this approach; that being without accommodation might contribute to health and other crises, seems to have also been discounted.

The results of the first National Evaluation led to a re-orientation of the program by focussing on what happened in SAAP in the longer period clients remained. In SAAP II, the objective was to provide:

transitional supported accommodation and related support services to people who are homeless and in crisis to help them move towards independent living, where appropriate, or other alternatives such as long term supported housing where possible (Lindsay 1993: 23; emphasis added).

The new emphasis on 'transition' has been retained in subsequent programs.

In addition to SAAP providing the site or space for monitoring and regulation, SAAP II heralded the onset of the 'time' in which this could occur - in transition. As the second evaluation put it: 
the aim of transitional services is to link SAAP users into generalist (and where necessary specialist) services in the community and to prepare them, where appropriate for a move back to independent living in the general community (Lindsay 1993: 30).

The time spent in transition was designed to connect SAAP users, for example, to domestic violence counselling, employment agencies, health, income support and social security agencies. As such agencies are vested (to varying degrees) with the power of the state, the potential for assessing, monitoring and regulating behaviour was enhanced.

Immediately following the quotation cited above, the second National Evaluation conceded that some SAAP users may not require the support provided in crisis services and that '[o]thers are often forced to remain in SAAP for longer than they need because of the lack of affordable, suitable housing (Lindsay 1993: 30-31; emphasis added). The Program was finessed to adapt to the lack of exit points. The consequent time under the gaze was more extensive than necessary for some and (while they were in transition in SAAP) more intensive.

The 1994 SAAP III Act (Commonwealth of Australia 1994) contained provisions regarding the responsibilities of service providers. These included assisting people who were homeless by providing case management and assessment and referral. It also included linking clients to government provided employment, educational and training, health and income support agencies. Responsibilities regarding what was previously the prime objective of SAAP, namely, agencies finding long-term secure and affordable accommodated for clients, was (relegated to) third on the list of responsibilities (Commonwealth of Australia 1994).

It might be argued that accommodation and housing in the private and public sectors are beyond the control of SAAP. In some ways that is the case as recognised by the second National Evaluation: 'the shortage of affordable, accessible housing is beyond the control of SAAP' (Lindsay 1993: 120). Nonetheless, it is not beyond the control of government policy as indicated by a raft of recommendations to government about providing more affordable accommodation in the same evaluation (Lindsay 1993: 120-121).

Thus, SAAP was being transformed from a program which provided the support required to move clients on to independent living to a program of transitional arrangements in SAAP for clients who could not be moved on because there were no place for them to go. The transitional arrangements might involve a client moving from emergency accommodation to short-medium term (3 months), with another move to longer term SAAP accommodation (up to 12 months). Further, the changes outlined are indicative of SAAP agencies having the potential for greater degrees of management because clients stayed longer than necessary. This is germane because it represents a change in the Program itself.

According to the Government's web-site: 
The review of SAAP II in 1993 highlighted a number of priority needs for the Program, including better information for evaluating program achievements, better linkages between SAAP agencies and non-SAAP service agencies, and improvements in service quality. It also recommended no longer specifying target groups, and a range of principles by which the next agreement be guided, including partnership, users' needs, flexibility, innovation and integration (CDF\&CS 2001; SAAP A Brief History).

So far the modification of SAAP from a short-term crisis and refuge program to a transitional program highlight the Program becoming increasingly intrusive. It also became increasingly concerned with managing and regulation, with the integration and co-ordination of government and non-government agencies which was encapsulated in the term 'case management' which then, in turn, became integral to SAAP III and IV (CDF\&CS 2001).

\section{Case management}

According to the third National Evaluation of SAAP, case management 'encompasses client identification and outreach, individual assessment service planning, linkage with request services, monitoring of service delivery and client advocacy' (SEAC and AHURI 1999: 83). The fifteen (15) functions of a case manager included:

assessment, goal setting, intervention and services planning, resources identification and indexing, linking clients with resources and services, monitoring service provision, reassessment, outcome evaluation, interagency co-ordination, counselling, therapy and advocacy (SEAC and AHURI 1999: 83).

Case management typifies the more intrusive nature of SAAP. As the third National Evaluation (SEAC and AHURI 1999: 86) argued:

Fundamentally, case management has changed the face of SAAP agencies from being insular and largely unaccountable (to their clients at least) to at least being challenged in their practices to become client focused. Implementation has seen a greater rigour in developing agency and client policies, in evaluating whether existing models of service are client focused, and in assessing whether staff are able to deliver case management approaches.

Case management is defended in many ways. Nonetheless, it is more intrusive, it does regulate clients and workers, even if the workers know case management (euphemistically) as 'support plans' (SEAC and AHURI 1999: 85).

At the time of the third National Evaluation, half of the clients agreed to such a plan, with 21 per cent declining case management. For another 30 per cent case management was 
deemed inappropriate (SEAC and AHURI 1999: 85). However, in SAAP IV the commitment to case management, and its concomitant, linking clients with other agencies (with similar practices), was re-affirmed and enhanced. Currently then, case management is increasing; the objectives are more refined, and the outcomes clearly stated to determine if they have been met (CDF\&CS 2001). Case managers manage clients even if by 'support plans'.

It might be argued that this is a positive step for clients. The Program is more focused toward clients; the SAAP goals are tighter making them more amenable to assessment. It might also be argued that connecting clients with other agencies is also efficacious in the process toward independent living. However, none of the above changes the greater depth of intervention; in fact, as shown, it is vaunted as a positive development.

Further, the third National Evaluation reported that among the appointed Case Management Advisors there was 'broad agreement that the implementation of the case management requires further development under any future response to the needs of the homeless' (SEAC and AHURI 1999: 87; emphasis added). Case management was also regarded as 'mandatory and not optional for agencies'. It was also the stated that case management 'should include the full spectrum of service, from early intervention and prevention to exit planning and follow-up' (SEAC and AHURI 1999: 87). Case management is on the increase.

In the context of the need for data on the efficacy of case management, the third National Evaluation concluded that it was important to assess the unique strengths of SAAP in delivering case management '... as it is likely that case management (by its nature) could increase the length of involvement of clients with services' (SEAC and AHURI 1999: 89; emphasis added). This is precisely what is being argued about case-management - that, reflective of SAAP overall, the developments over time have increased the period of intervention and its nature.

Thus far we have seen how the lack of exit points have operated in SAAP. They have not only resulted in people remaining in SAAP longer than is necessary (the point of the previous section) but, along with policy changes, they have resulted in more intrusive work with clients. In other words, the net result of developments in SAAP (partly attributable to the lack of exit points) is that the work with clients is not only more extensive but it is also more intensive.

\section{Other issues reflecting changes in SAAP}

Debates about the meaning of 'support' in the supported Accommodation Assistance Program

One issue which has arisen in SAAP is the meaning of 'support' in supported accommodation. This is very interesting because the modifications in this area parallel the increasingly interventionist nature of the program. Initially 'support' was regarded as that which would otherwise be provided by networks of family and friends and which is 
not available to people who are homeless. As the first National Evaluation (Chesterman 1988: 47) recommended: 'The support services provided by SAAP should provide a temporary substitute for or enhancement of their own support network. Treatment or long-term specialist services are not included.'

In this way the first National Evaluation reflected the original purpose of SAAP. The 'support' provided was low key, informal, 'a temporary substitute' to that of family and friends. By the second National Evaluation there was another development, namely, the re-conceptualisation of 'homelessness' as an increasingly complex 'problem'. It was claimed that without the support provided by SAAP, which varies in type, intensity and duration according to need, many SAAP users would be destined to a continuing cycle of poverty and homelessness (Lindsay 1993: 44). By the time of the third National Evaluation, 'support' really meant 'case management'.

Debates about independent living

A related issue which also exemplifies the changes in SAAP is the debate about the meaning of 'independent living'. This is significant because it rela tes to the prime SAAP objective, namely, enabling SAAP clients to move on to independent accommodation. In SAAP I, the moving-to-independent-living objective had a 'significant impact' on SAAP. As the report of the first National Evaluation noted:

Given the diversity of the SAAP target population, it is inappropriate to provide a hard and fast definition of "independent living". However there is considerable agreement that its attainment is a positive outcome of the provision of services (Chesterman 1988: 44; emphasis in original).

The main change in SAAP II was the increase in support external to SAAP accommodation; support was not restricted to SAAP facilities. This involved workers providing support in the post-SAAP independent living arrangements (Lindsay 1993: 75, 45-46). However, the transition to independent living objective remained.

However, by the third National Evaluation there was some doubt about whether the independent living objective was appropriate (SEAC and AHURI 1999: 93). The evaluators agreed that independent living depended on:

an individual's capacity to fully participate in community life as an integral part of being able to live independently brings with it the suggestion of access to stable and appropriate housing. For the homeless, quite clearly access to requisite income and housing along with increased access to employment is critical in developing the capacity to live independently (SEAC and AHURI 1999: 93).

This notwithstanding, the evaluators also stated that it was 'arguable whether the objective of independent outcomes is appropriate' claiming that it was too broadly cast to be a useful aim' (SEAC and AHURI 1999: 106). 
Not surprising in light of the above analysis, the report urged the need for more 'overseeing and reviewing [of] service design'. It argued that it should be made explicit 'that government has a responsibility to support services in their attempts to provide innovative, effective, efficient client service' (SEAC and AHURI 1999: 106). In other words, rather than the emphasis on accommodation, case management, forging links between agencies and more co-ordination, are the ways to realise the independent living objective.

Thus, in the context of a more extended period in SAAP accommodation, and more intensive support in the form of case management, the debates about 'support' and 'independent living' are significant. 'Support' became case 'management' and the relevance and meaning of the 'independent living' objective was questioned.

\section{Comments on several implications of analysis}

In this section I take the opportunity of addressing several issues which have arisen in the course of the paper. $^{2}$ The first concerns the emphasis on what has been done to clients rather than their reactions and responses to it. In other words, I have emphasised the structures which impact on individuals without a corresponding examination of agency.

While this criticism has been made of Foucault, his work, and particularly his later work, attests to a keen interest in agency. Thus in addition to 'technologies of power' directed by structures and institutions at individual people, Foucault also explored what he called 'technologies of the self', namely, those technologies which:

permit individuals to effect by their own means or with the help of others a certain number of operations on their own bodies and souls, thoughts, conduct and way of being, so as to transform themselves in order to attain a state of happiness, purity, wisdom, perfection of immortality (Foucault 1988: 18).

The above analysis has not followed Foucault's concept because the emphasis has been on the increased potential and the consequences of surveillance.

However, the response of clients in some specific areas is known. For example, we know that 'housing/accommodation' was 'a support need for 85 per cent of SAAP clients' (SEAC and AHURI 1999, p. 86). We know that '[c]lients typically want housing' (SEAC and AHURI 1999, p. 46). For all the co-ordination and case management, the fundamental stated housing need of clients has not been attenuated. Further, and as noted, while half of clients agreed to case management, one-fifth did not. This is one of the few indicators of any form of resistance in the modifications to SAAP.

These are but two faint indicators of agency. If such agency were to feature in such an analysis more ethnographic approach (involving, at least participant observation and

\footnotetext{
${ }^{2}$ Several of the issues mentioned were raised by the referees. In acknowledging them, I also thank them for raising the issues.
} 
interviewing) would be required. This approach would attempt to analyse how individual clients interpreted, coped and complied with, or resisted the more extensive and intensive intervention. Sadly, very little research in this area has been undertaken.

A second issue which I mention at this stage concerns the fact that the diversity of people who are homeless, and possible implications for the argument which might follow, have not been examined. A certain homogeneity is tacit in my analysis. So the people who are homeless have not been disaggregated into people who are homeless by sex, household (single, couple, families, with children) or whether or not they have issues with drugs, health, or mental health. This is a focus of future research.

However, it might be claimed that by not exploring the heterogenous nature of people who are homeless, contact with other (non-SAAP) agencies has been assumed and, moreover, assumed to be uni-direction. In other words, I have assumed that the interaction between, for example, homeless people with a mental illness, on the one hand, and government agencies, on the other, has only occurred while in SAAP.

It is the case that the categories of people who are homeless have not been disaggregated in the above analysis. It is also the case that some SAAP clients may have come under the gaze of other government authorities before and after their time in SAAP. However, the argument in this paper is that whatever contact people who are homeless may have had with social security (Centrelink in Australia) or health or housing authorities before SAAP, is compounded by the unnecessary time spent in SAAP, the changes to SAAP, and case management. The compounding mentioned is at least two-fold: in SAAP, and between SAAP and other agencies, in the process of increased co-ordination and case management.

Thirdly, it might also be argued that increasing support for people who are homeless increases the likelihood of moving to independent accommodation; the more support the better the chances of moving on. This is precisely what the third National Evaluation claimed (SERC and AHURI, 1999: 100, 105). It is not a surprising conclusion. However, as indicated, the same National Evaluation also concluded that it is the lack of exit points that kept clients in SAAP longer than necessary (SERC and AHURI 1999: $53,105,57)$.

The salient point is not so much that more support increases the likelihood of independent living. It is that such independence could have been obtained sooner if exist point were readily available - and with even less support (the euphemism for case management) and the concomitant normalisation and regulation!

Finally, another issue which arises from the above analysis is why the state seems to prefer to pay to keep people in SAAP for longer periods rather than provide the affordable and appropriate housing they desperately need. Surveillance, control, regulation and normalisation seem to come at a huge monetary price. However, there are at least two explanations for the state/public funding of SAAP. 
Firstly, SAAP can be seen to perform certain social functions including (a) defending the discourse of personal inadequacy and deficiency as the cause of homelessness, and (b) keeping people off the streets while (c) the backlog caused by the lack of exit points means that the 'problem' is sufficiently visible to justify government intervention. Secondly, to provide more affordable housing would not only mean direct or indirect government intervention in the housing market, it would also mean using funds which prop up the private sector, such as large subsidies to first home buyers, and tax deductions on loans and related costs for investors (known as negative gearing). Arguably, SAAP is one program which, simultaneously, advances the aim of seemingly increasing welfare, internal surveillance and security while buttressing the private housing sector when de-regulation (and therefore less public housing) is a major government objective.

\section{Conclusion}

There is little doubt that SAAP has afforded some safety and security by providing accommodation for people who are homeless. SAAP has prevented some people from sleeping outdoors or in a squat or car. This should be recognised. Further, the analysis does not necessarily caste doubt on the many workers in the sector who, even when paid agreed wages, work long and hard hours. Many also disseminate the problems associated with the paucity of exit points in whatever forum they can, and work under considerable pressure to realise outcomes and performance indicators (when the lack of exit points makes it all the more difficult to achieve independent living and other objectives for clients).

If the above analysis has implications for any group, it is for the highest level of decisionmaking, namely governments and their very highest-ranking advisors. The analysis is neutral with regard to party politics in Australia because both Labour and Liberal parties have (at different times when in office) overseen the developments identified.

The above analysis has identified the implications of the lack of exit points, and the increasing potential for extensive and intensive surveillance, monitoring and regulation toward one of Australia's most disadvantaged and marginalised groups. But it is not only the lack of exit points, and remaining in SAAP longer than is necessary, which have been identified as contributing to this normalisation.

There have been changes to SAAP which have also been part and parcel of the increasing surveillance and regulation including changes from crisis to transition, from 'support' to 'case management', and debates about the very possibility of independent living for this client group. Thus, SAAP does have the potential to be a laboratory of power' in much the way Foucault analysed; technologies of discipline are used in much the same way Foucault described in other institutions.

What is particularly salient is that the changes in SAAP are at least partly the result of the lack of exit points. One way of reading such changes to SAAP is to regard them as 
adaptations to deal with the problem of clients remaining in SAAP for longer than is required simply because there are so few external accommodation and housing options. Home ownership is impossible for clients. Private rental is too expensive for ex-SAAP clients, and the public housing system has contracted so that demand outstrips supply and waiting lists are long. The lack of exit points is the result of government policy, the subsidising and privileging of home-ownership and the private rental sector - all of which can be traced to free market policies of economic rationalism and neo-liberalism.

Yet the broader housing issues are significant for SAAP clients. With this in mind the policy implications are clear - there is an acute need for more affordable and appropriate housing. In the meantime, the surveillance and technologies of power are enhanced in SAAP; surveillance tends to supervision, and (what might some might consider) care mutates into control.

\section{References}

Cheek, J. and T. Rudge (1993) The power of normalisation; Foucauldian Perspectives on Contemporary Australian health Care Practices. Australian Journal of Social Issues, 28(4): 271-284.

Chesterman, C., (1988), Homes Away from Home: Supported Accommodation Assistance Program Review. Canberra: AGPS.

Commonwealth of Australia, Supported Accommodation Assistance Act (1994) Last update unavailable; $22^{\text {nd }}$ May 2002:

http://scaletext.law.gov.au/html/comact/8/4450/0/CM000150.htm

Commonwealth Department of Family and Community Services (DCF\&CS) (2001) SAAP - Supported Accommodation Assistance Program - SAAP A Brief History, Last up-date unavailable; $22^{\text {nd }}$ May 2002:

http://www.facs.gov.au/internet/facsinternet.nsf/aboutfacs/programs/saap4

Commonwealth Department of Family and Community Services (DCF\&CS) (2001a) Supported Accommodation Assistance Program National Strategic Plan 20002005, Last up-date unavailable; $22^{\text {nd }}$ May 2002:

http://www.facs.gov.au/internet/facsinternet.nsf/b919d06b2c7d99e3ca256807001 393b2/30a48d7e7def0027ca256a61001c1151/\$FILE/NatStratPlan

Dreyfus, H. L. and P. Rabinow (1982) Michel Foucault: Beyond Structuralism and Hermeneutics. London: Harvester Wheatsheaf.

Fopp, R. (1996) 'No where to go: an analysis of the Supported Accommodation Assistance Program', Australian Journal of Social Issues, 31(2): 209-222. 
Foucault, M. (1974) The Order of Things: An Archaeology of the Human Sciences. London: Routledge.

Foucault, M. (1979) Discipline and Punish: The Birth of the Prison. Harmondsworth: Penguin.

Foucault, M. (1982) The Subject and Power. In H. L. Dreyfus, and P. Rabinow (1982) Michel Foucault: Beyond Structuralism and Hermeneutics, Harvester Wheatsheaf, London: 208-226.

Foucault, M. (1988) Technologies of the Self, A Seminar with Michel Foucault. Ed. L. H. Martin, H. Gutman, and P. H. Hutton. Amherst: The University of Massachusetts Press.

Foucault, M. (1991) The Foucault Reader: An Introduction to Foucault's Thought. Ed. P. Rabinow, Harmondsworth: Penguin.

Hoy, D. C. (ed.) (1986) Foucault: A Critical Reader. Oxford: Basil Blackwell.

Lindsay, M (1993), Moving Forward, National Accommodation Assistance Program. Canberra: AGPS.

The Social and Economic Research Centre and The Australian Housing and Urban Research Institute (SEAC and AHURI) (1999) National Evaluation of the Supported Accommodation Program (SAAP III), Canberra, Department of Family Services. Last up-date unavailable; $22^{\text {nd }}$ May 2002: http://www.facs.gov.au/saap/nat_eval.htm

Neil, C. and R. Fopp (1994) Homeless in Australia, Causes and Consequences. Melbourne: Australian Housing and Urban Research Institute.

Rabinow, P. (1991) 'Introduction' to The Foucault Reader: An Introduction to Foucault's Thought, ed. P. Rabinow, Harmondsworth: Penguin.

Shawver, L (1988) Dictionary for the Study of the Works of Michel Foucault, 21 March 1999. 22 May 2002: http://www.california.com/ rathbone/foucau10.htm 